\title{
Pergunta-resistência: A que veio o CRAS?
}

\author{
Resistance - question: What did CRAS come for?
}

Paulo Armando Esteves Martins Viana; Claudia Elizabeth Abbês Baeta Neves

Universidade do Estado do Rio de Janeiro; Universidade Federal Fluminense

\section{RESUMO:}

$\mathrm{O}$ artigo objetiva 'tensionar' o funcionamento da política de Assistência Social no contemporâneo, partindo de perguntas-resistência que problematizaram as táticas de gerência/governo dos corpos que habitam os 'ditos' territórios vulneráveis e de risco onde se inserem os equipamentos da Assistência Social. As análises foram tecidas articulando à produção histórico-política dos conceitos que embasam a atual Política Nacional de Assistência Social (2004) as interpelações advindas de perguntas-resistência, enunciadas por personagens surpreendentes e imprevisíveis, que colocaram em circulação problemas e questões importantes no funcionamento desta política no contemporâneo. A aposta políticometodológica afirmada possibilitou um exercício de escuta-experimentação como abertura aos movimentos da vida que se forjam em meio àquilo que a pretende naturalizada.

Palavras-chave: Política de Assistência Social; vulnerabilidade social; biopolítica.

\section{ABSTRACT:}

The article aims to tense the functioning of the Social Assistance Policy in the contemporary starting from resistance-questions that problematized the management / government tactics of the bodies that inhabit the vulnerable and risky territories where the Social Assistance equipment is inserted. The analyzes were made articulating to the historical-political production of the concepts that underlie the current National Social Assistance Policy (2004) the interpellations from resistance-questions, enunciated by surprising and unpredictable characters, which put into circulation problems and important issues in the functioning of this politics in the contemporary. The affirmed politicalmethodological bet made it possible to exercise listening-experimentation as an opening to the movements of life that are forged in the midst of what is intended to be naturalized.

Key-words: Social Assistance Policy; social vulnerability; biopolitics.

DOI: 10.12957/mnemosine.2021.61865 
Este artigo se origina de uma pesquisa de mestrado $^{1}$ que teve por objetivo tensionar práticas instituídas no campo da assistência social e os conceitos constitutivos da atual Política Nacional de Assistência Social (2004). A pesquisa, de cunho qualitativo, foi realizada num Centro de Referência da Assistência Social (CRAS), localizado numa cidade do interior do estado do Rio de Janeiro, e partiu das experiências de trabalho do primeiro autor, psicólogo do CRAS, vivenciadas junto a profissionais e usuários de um CRAS. A inserção do trabalhador-pesquisador, tornado pesquisador-trabalhador, no CRAS, possibilitou a criação de problemas incitados pelos ruídos daqueles que lá habitam (profissionais, usuários e gestores), colocando em análise a função naturalizada do equipamento citado, bem como os conceitos que lhes dão suporte. Tal análise foi tecida a partir de uma aposta político-metodológica que se utilizou de perguntas insistentes, que aqui chamamos de perguntas-resistência, enunciadas por personagens surpreendentes e imprevisíveis que colocaram em circulação problemas e questões importantes no funcionamento da política de Assistência Social no contemporâneo.

Nesta pesquisa utilizamos como caminho metodológico a Pesquisa Cartográfica e a Pesquisa-Intervenção, tendo como finalidade o acompanhamento e a interrogação das práticas naturalizadas que se materializam nas práticas sociais, por meio da análise das instituições em cena e movimentos instituintes produzidos no campo. A cartografia é um método de estudo-intervenção do/no socius, proposto por G. Deleuze e F. Guattari (1995), que nos convoca a uma experimentação problematizadora no acompanhamento dos processos de composição e decomposição de uma realidade ou matéria, apreendendo-a em seus índices imateriais e movimentos conectivos na produção do socius e dos modos de subjetivação. Neste sentido, implica menos a apreensão da realidade como matéria de desvelamento ou cognição, e mais a afirmação da realidade em sua potência de abertura de sentidos e invenção. Um fazer cartográfico requer um aprendizado da escuta e da atenção às forças do presente que trazem o novo em seu caráter disruptivo e nos possibilitam indagar: que espécie de vida este e/ou aquele agenciamento promove? O método, sob este aspecto, diz respeito a um dispositivo de ampliação de visibilidades e de expressão do próprio campo problemático em questão. Toda produção de realidade é dinâmica, complexa e efeito de uma dispersão de movimentos-acontecimentos 
(FOUCAULT, 2011) que, em seus efeitos e conexões, expressam o campo problemático no qual se inscreve. O campo problemático nos possibilita analisar os acontecimentos em seu misto, ou seja, naquilo que portam como atualização de visibilidades, dizibilidades e expressão no estado de coisas e no que enunciam como virtualidades provocadoras de estranhamentos, rupturas e inflexões que alteram e ampliam a sensibilidade aos regimes de visibilidades e expressão instituídos em modos de ser, fazer e sentir a realidade.

$\mathrm{Na}$ pesquisa-intervenção, pesquisador e pesquisado, sujeito e objeto do conhecimento se constituem ao mesmo tempo, no mesmo processo; deste modo, as práticas produzem os objetos assim como modos de subjetivação, não há determinação causal de um sobre o outro. O que aqui recusamos é a noção de dado auto-evidente, esteja ele num sujeito constituinte a quem caberia dar conta dos objetos possíveis de conhecimento, ou mesmo na idéia de uma abstração do sujeito em prol da objetividade pura, pois nos encontramos em conexão com modos de objetivação e subjetivação que acionam certo funcionamento, onde a dicotomia tradicionalmente instituída entre sujeito e objeto perde o sentido (LOURAU,1993). A pista que tomamos aqui diz respeito à investigação do funcionamento dos processos de regulamentação da vida nas práticas de cuidado produzidas na implementação de políticas públicas de assistência, atentos aos modos como profissionais e usuários desviam das vidas prescritas, construindo, em meio às prerrogativas normalizadoras destas políticas, outras normatividades e perguntas-resistência.

\section{A que veio o CRAS?}

Segundo a Política Nacional de Assistência Social (PNAS/2004), o CRAS é um equipamento público, preconizado como porta de entrada do Sistema Único de Assistência Social (SUAS), cujo objetivo seria "prevenir situações de risco por meio do desenvolvimento de potencialidades e aquisições, e o fortalecimento de vínculos familiares e comunitários" (PNAS/2004:33).

O público-alvo desta política é constituído por grupos e indivíduos considerados em situação de vulnerabilidade social "decorrente da pobreza, privação (ausência de renda, precário ou nulo acesso aos serviços públicos, dentre outros) e/ou fragilização de vínculos afetivos - relacionais e de pertencimento social (discriminações etária, étnica, de gênero ou por deficiências, dentre outras)" (PNAS/2004: 33). 
Os conceitos de vulnerabilidade social, risco pessoal/social, prevenção, território e controle social que sustentam os dispositivos operacionais desta política indicam a necessidade de uma apreensão dos mesmos na complexidade de suas formalizações, seja pelas práticas socioassistenciais que lhes dão suporte, seja pelos atores que a atualizam.

Pudemos então observar, na experimentação deste trabalho, que profissionais/usuários tanto podem reproduzir a lógica imposta, que naturaliza o enquadre de modos de vida em alvo de tutela e controle, quanto, em alguns momentos, resistir às formas propostas, legitimando práticas outras que embaçam a lente voraz dos regimes que sobrecodificam a vida e a transformam em objeto.

Tais experimentações serão apresentadas através dos fragmentos dos diários de campo/bordo que narram vidas em seus movimentos, torções e tensionamentos. Narram aquilo mesmo que as desqualifica e as lamina em mensurações que as querem previsíveis, vulnerabilizadas e transformadas em matéria de governo, objetos de intervenção e de práticas tutelares.

Os fragmentos de cena escrita, recheados de perguntas insistentes, enunciadas pelos usuários do serviço, colocam em circulação problemas, questões importantes no funcionamento da política de Assistência Social no contemporâneo. Seus modos de operar, suas táticas e estratégias de gerência/governo dos territórios, e os corpos que lá habitam são pinçados pelas experiências/perguntas que se apresentam.

No primeiro ano de funcionamento do CRAS onde trabalhamos, uma usuária, ou pretendente a usuária do serviço, fez uma pergunta: “A que veio o CRAS?”. Na época, provavelmente, a questão foi respondida da maneira prescrita, conforme ainda hoje respondemos nos momentos de maior agonia ou impaciência: "equipamento público que objetiva intensificar o diálogo intersetorial e garantir o acesso aos direitos sociais".

Atualmente, a pergunta insiste e nos provoca novas angústias, e outras respostas. Aliás, temos inclusive problematizado a demanda por tal resposta, ou se tal pergunta requer, de fato, uma resposta. “A que veio o CRAS?" é uma pergunta; sua resposta é 'muito', por isso desequilibrante, tensionante, perturbadora de fazeres. Pois, ao questionar conceitos básicos e unânimes no campo da política pública, a saber, território, descentralização político-administrativa e controle social, levanta fervura, desposiciona, reposiciona, produz ferramentas, gagueiras e gaguejos. 
Quando se faz necessário perguntar sobre sua chegada, é porque o CRAS simplesmente veio, e aí é que reside o problema, o nó e a fechadura, dura, dura, dura. Veio como, para fazer o que, para quem? A que veio? Pergunta inaugural para o dispositivo, mas insistente e persistente para aqueles que ali vivem. Diríamos: pergunta-resistência.

Seria necessário respondê-la? Se respondermos, em primeira pessoa, também assumimos sua autoria. Então, façamos outro caminho. Propomos acionar a perguntaresistência e tensioná-la em seus fazeres. São muitos.

A pergunta é de todos: profissionais, gestores, usuários. E os primeiros costumam responder: "Veio para fomentar maior comunicação entre os serviços públicos, garantir direitos, intersetorialidade, promover acompanhamento socioassistencial, preencher guias de contra-referência e relatórios. Ah! Também serve para produzir dados e conhecimentos sobre a vulnerabilidade social, bem como construir mecanismos para prevenir situações de risco que decorram desta condição social".

Esta é uma possibilidade de resposta que se prolonga, se torna um regimento, se atualiza, se configura hegemonicamente. Permite a emergência de (uma) escuta, de (um) estatuto, favorecendo o enquadramento da população/grupos localizáveis em diferentes públicos-alvo, diferentes atendimentos, diferentes demandas, diferentes benefícios, diferentes condicionalidades, excepcionalidades, overdose de acessórios e focalização ou focalizações.

E as práticas que operacionalizam o CRAS? As visitas domiciliares, os grupos reflexivos, os atendimentos no serviço? É justo aí, em meio a este processo, que reside a pergunta: A que veio o CRAS? Esta, poderíamos dizer, se faz uma questão ética, pois tensiona o regime de inteligibilidade biopolítico $^{2}$ e a experiência com todos os seus sussurros e berros.

Pretendemos usar esta pergunta-resistência como desbravadora deste território pouco percorrido da Política Pública de Assistência Social em seus conceitos primordiais.

Tal afirmação metodológica (perguntas-resistência) dialoga com uma conceituação de poder que pegamos de empréstimo a Foucault (2005). Para o autor, o próprio poder é uma relação, não se colocando, portanto, em exterioridade àquilo que produz ou que o produz. Ou seja, ele transforma a pergunta direcionada ao poder feita durante tanto tempo 
pelas correntes clássicas da filosofia e pelo marxismo: de "o que é" o poder para o "como" do poder.

Sendo assim, a pergunta passa a produzir novos problemas, questionando, portanto, todo e qualquer posicionamento teórico que remenda o poder através da opressão, repressão ou contratualidade. Todos esses variantes garantem certa relação de possessividade em relação ao poder, sua identificação e centralização. Foucault (2005) explica:

[...] no caso da teoria clássica do poder, o poder é considerado um direito do qual se seria possuidor como de um bem, e que se poderia, em consequência, transferir ou alienar [...] que seria da ordem da cessão ou do contrato [...]. No outro caso, claro, eu penso na concepção marxista geral do poder [...] que se poderia chamar de "funcionalidade econômica" do poder [...] na medida em que o papel essencial do poder seria manter suas relações de produção e, ao mesmo tempo, reconduzir uma dominação de classe que o desenvolvimento e as modalidades próprias da apropriação das forças produtivas tornaram possivel (FOUCAULT, 2005: 19-20).

Ou seja, em sendo crítico a esses posicionamentos, Foucault argumenta que o poder se exerce, só existe em ato e afirma que este não é a manutenção ou reprodução de uma relação econômica, mas é em si mesmo uma relação de força. Assim, o poder, em sendo tático e estratégico, estabelece regimes e modos de funcionamento. Em suas relações com o saber, compõe verdades; contudo, estas composições se fazem em meio a exercícios, cuja exposição e visibilização se dão em meio a relações de forças.

É só aí, no cerne destas relações, que se vislumbra uma resistência, pois, se o poder como exercício não se presta a análises funcionalistas, mas faz ver e dizer de seus funcionamentos em ato, poderíamos, portanto, dizer que tal análise requer a explicitação das forças em combate e seus modos de enfrentamento.

Heckert (2004) nos alerta que as resistências podem ser pensadas como linhas desobedientes que problematizam as ordenações, que se insinuam por meio de personagens anônimos que interrogam as proposições, alterando as rotas através de estratégias surpreendentes.

A autora nos ajuda a pensar que resistir não é reagir. Resistir é inventar, é abertura, é ranhura, é rascunho, é rabisco, é cheiro e é resto também. Resistir é narrar a vida por sensações. Resistir é cortar - abertura de frestas oxigenantes. Ficcionar, dissimular e tropeçar: as perguntas-resistência têm essa força, porque não são meros conceitos, mas 
práticas em exercício e em constante relação de vizinhança com outras que a ancoram (VEYNE: 1978). Nas palavras de Heckert (2004):

(Resistência) É uma abertura infinita que sinaliza que as formas são contingenciais, $e$ não permanências eternas. Possibilidade de vislumbrar criações nos restos, detritos e sucatas que povoam este espaço. Práticas de resistência são aquelas que não apenas atendem ao prescrito, ao designado, ao já esperado, mas que no seu fazer esboçam outros modos de ação. Tais modos, muitas vezes imprevisíveis, são impossíveis de serem programados e funcionam como foco irradiador que se conecta a outras práticas (HECKERT, 2004: 27).

Portanto, para pensarmos a Política Pública de Assistência Social no Brasil, é necessário fazer emergir certo campo de forças, onde se encontram diferentes linhas (suas ranhuras e diagramações) que permitem a aparição do social como campo de intervenção e reconhecimento de problemas. Gilles Deleuze, ao escrever o prefácio da obra de Donzelot (2001), explica que o social "nem se confunde com o setor público ou com o setor privado pois induz, ao contrário, uma nova figura híbrida de público e privado, produzindo ele mesmo, uma repartição, um entrelaçamento original entre as intervenções do Estado e seus recuos, seus encargos e desencargos (DELEUZE, 2001: 2).

Ou seja, o campo que, a partir do século XVIII, passa a ser o alvo específico das políticas sociais é um híbrido, uma imbricação de setores, de discursos e de linhagens. Não é dotado de neutralidade, nem de natureza, é um campo político, onde se instauram normas em consonância com os regimes de verdade que se querem homogêneos e universais. (SILVA,2005).

Os autores acima utilizados nos ajudam a entender que analisar a política de Assistência Social não implica em reconhecê-la, encontrá-la ou desvelá-la a partir da letra da lei. Mas, diferente disto, atentar para seus hibridismos e diferentes linhagens requer entendê-la a partir de seus efeitos, pois ela mesma é um efeito desses regimes de verdade que circunscrevem os modos de operar seu funcionamento.

Dizemos isso para garantir a compreensão de que a Assistência Social como política social não pode ser entendida de maneira ensimesmada; ao contrário, a situamos em um plano relacional em que, a partir do vislumbre de suas táticas e tecnologias, bem como os movimentos de resistência - em meio ao qual emergem as práticas de assistência - é que poderemos traçar/desenhar seu percurso. 


\section{Esfiapando a Assistência Social}

Há algum tempo, nós, equipe do CRAS, fizemos uma visita domiciliar por solicitação de uma gama de atores (Família, Estratégia Saúde da Família e Secretaria Municipal de Assistência Social) que consideravam a vida de um senhor idoso indigna de ser vivida.

Ele é alcoolista, velho, mora só, apresenta dificuldades de locomoção, complicações vastas de saúde, não possui benefícios (Programa Bolsa-Família ou Beneficio de Prestação Continuada), contribuiu por um tempo irrisório ao INSS. Cai e se machuca quando está alcoolizado, e fala sem parecer nos ouvir, expressando-se apenas pelo balançar afirmativo de sua cabeça. Com este gesto, o senhor responde às sugestões de colaboração por parte do CRAS: "O Sr. entendeu?”; e o gesto se apresenta de novo e cada vez mais cansado.

E se dissesse não? E se pudesse nesta negativa simplesmente afirmar-se frente a tantas perguntas para as quais muitas vezes não tem respostas ou que sequer lhe produzem algum sentido? Muitas foram as possibilidades de colaboração e propostas 'restauradoras' visando dar-lhe "um projeto de vida'. Que projeto, que vida? Um "não" assinalaria uma indolência confirmadora de um risco? A efetivação da necessidade de sua tutela que o qualificaria como incapaz, cabível de uma interdição?

Ele "prefere" o sim. Que parece favorável às ofertas recebidas, mas sugere também um modo de "encurtar a prosa". Na despedida, já no portão, apenas nos diz: "Minha vida está por um fiapo!”. O que neste encontro produziu essa enunciação?

A política de assistência social tece sua rede de serviços a partir do diagnóstico de vulnerabilidades socioterritoriais. Este senhor reúne algumas condições que o elevam à condição de vulnerável social, visto que é idoso, alcoolista e apresenta dificuldades de saúde que comprometem sua locomoção e autonomia. Ele precisa, segundo as normativas desta política, ser enquadrado em um serviço, "ser" restituído a uma cidadania, ou simplesmente ter comprovada sua impotência. O Manual de Orientações Técnicas (2012) para atuação no CRAS nos dá uma pista:

$O$ acompanhamento [...] é destinado às famílias que apresentam situações de vulnerabilidades que requerem a proteção da assistência social para garantia de seus direitos socioassistenciais, acesso aos direitos sociais e ampliação de sua capacidade protetiva, demandando, para isso, uma atenção diferenciada, um olhar mais atento dos profissionais do CRAS, na medida em que essas situações vivenciadas, caso não sofram imediata intervenção profissional, podem tornar-se risco social elou violação de direitos (MANUAL DE ORIENTAÇÕES TÉCNICAS, 2012:50). 
Desta forma, constrói-se em meio aos manuais e conceitos apresentados uma institucionalidade da vulnerabilidade que dá sustentação às práticas agenciadas pelos profissionais atuantes no CRAS. A vulnerabilidade ganha vida e institui vidas. Mas ele afirma: "Minha vida está por um fiapo". Entrelaçados pelo dito e pelas assertivas proclamadas pela política de assistência social, problematizamos o caráter paradoxal da afirmação: "Minha vida está por um fiapo".

Fiapo como degradação da vida biológica e/ou afirmação de um projeto outro de vida? O que nos diz sua fala, "Minha vida está por um fiapo!", e o repetitivo balançar de cabeça? Trata-se da fragilidade de suas condições e modo de vida ou, talvez, diga dos riscos em que o colocamos ao inseri-lo nesta rede tutelar socioassistencial? No que tantas propostas e perguntas esfiapam seus respiros, provocando a gesticulação automática?

Vidas-fiapo tensionam a Política de Assistência Social em seus dispositivos de qualificação da vida dos "assistidos". Nestes tensionamentos é que pensamos tal política, atentos ao que está para além e aquém dos efeitos produtores de gesticulação automática.

Consideramos, portanto, importante compreender as práticas da assistência social em seus 'fiapos' constituintes, atentos a como ela responde às indeterminações da vida e como esta resiste às suas determinações.

A Assistência Social é acionada numa complexa relação de forças, uma rede produtora de práticas e de vidas demandantes. Ela emerge junto mesmo daquilo que produziu o social como questão, associada a toda uma gama de problemas políticosubjetivos referentes ao modo de produção econômico capitalista. Eram precisos dispositivos de controle da vida qualificada como indisciplinada, desempregada, arruaceira, vagabunda e sem limites.

Sendo assim, a Assistência Social modula-se para dar conta desta demanda que individualiza/naturaliza os ditos problemas sociais do capitalismo. Ela precisa produzir no velho uma necessidade de dependência e tutela. Espera-se dele um consentimento e, da assistência social, a visibilização de sua falha moral, orgânica e de sua fragilidade, qualificando-se, assim, ‘a vida como fiapo' em 'fiapo' de morte. 


\section{Da Assistência Social no Brasil: Filantropia, Medicina Social e Normalização da} População.

Tomamos aqui a assistência social como prática, visto que agencia dispositivos discursivos e não discursivos que produzem objetos sobre os quais ela opera. Tal prática assume diferentes configurações na medida em que as relações de poder se modulam. Portanto, a assistência social pode assumir vieses filantrópicos e/ou ser compreendida como política de estado, dependendo das alianças que são forjadas em meio àquilo que é objetivado como problema e questão social.

Neste quadro, tomaremos de empréstimo algumas discussões de autores que vêm pontuando a assistência social em seus diferentes aspectos constitutivos, tanto numa abordagem político-econômica do social como campo de intervenção, quanto nos processos de subjetivação que se efetivam em seu exercício.

De acordo com autoras do campo da assistência social, Behring e Boschetti (2011), cabe compreendermos a caracterização da formação do capitalismo no Brasil para se pensar o surgimento e o desenvolvimento das políticas sociais em nosso país. Estas se deram de maneira díspar em relação aos países europeus, já que não fomos o berço da Revolução Industrial e, portanto, as relações sociais pautadas num modo de produção capitalista desenvolveram-se também de maneira diferenciada, remontando ao final do século XIX.

Podemos afirmar, com isso, que a constituição das políticas sociais apresenta tensionamentos que se singularizam em meio a processos de subjetivação, e políticas socioeconômicas, marcados pela complexa dinâmica dos movimentos internos da economia e sociedade brasileiras.

As autoras destacam que o colonialismo e o imperialismo são momentos importantíssimos da formação político-econômica brasileira, caracterizando uma sociedade e uma economia que se organizam para fora, conformando sua economia a interesses e mercados estrangeiros. Além disso, o escravismo figura-se como aditivo de extrema importância, visto que foi agente de desqualificação da condição de trabalho nas relações sociais.

Tal situação, conforme nos explicam Behring e Boschetti (2011), retardou a ação política dos trabalhadores livres no Brasil, cujas primeiras manifestações datam do início do século XX. "Estas, quando se colocam mais adiante na cena política, extrapolando o 
mandonismo e paternalismo tradicionais das elites, serão tratadas a partir da repressão policial e da dissuasão político-militar" (p. 77).

Lobo (2008), trazendo outra perspectiva de análise, não circunscrita aos movimentos que tiveram lugar na história oficial, afirma que é neste período (início do século XX) que a elite brasileira começa a atentar para os riscos que o sistema de trabalho nas fábricas (inaugurado pela adaptação ao capitalismo ocorrida no Brasil) permitia emergir. Esse risco tem expressão nas greves e paralisações de trabalho organizadas pelos operários. Desta forma, "era preciso ir além da disciplina estrita, da vigilância despótica sobre o comportamento operário e da aliança com a força policial" (LOBO, 2008: 337). Pois, até o final do século XIX, pobreza, ineficiência para o trabalho, infância, maternidade, ainda não eram consideradas questões a serem controladas pelo Estado ou objeto das estratégias médico-filantrópicas. Sendo assim, uma nova estratégia de controle dos corpos emerge:

Atingir a criança, o futuro trabalhador, higienizar os hábitos maternos, interferir nas relações familiares e no espaço doméstico foi uma tática bastante eficaz não só para prevenir novas transgressões, como para abrandar as rebeliões dos adultos às imposições dos patrões e evitar que as associações de autoproteção ao desamparo do trabalhador ganhassem caráter combativo de defesa e conquista de seus interesses. A intervenção era feita através de visitas domiciliares. Ao contrário da caridade, que levava à casa do pobre o pão para os que tinham fome e a palavra de Deus para os espíritos famintos, as visitadoras distribuíam conselhos de moral e higiene e propagavam os princípios da obra filantrópica. Enquanto o Estado não assumiu a responsabilidade pela assistência, a filantropia, atuando praticamente sozinha, viveu dos corações generosos dispostos a manter suas obras (LOBO, 2008:337).

Donzelot (2001), ao analisar, na França, a emergência do social como foco de preocupação do Estado, nos ajuda a pensar que há uma tendência, iniciada no século XIX, de se governar famílias e indivíduos a partir de um polo assistencial filantropo (uma conjugação entre o Estado liberal e a capilarização de técnicas de gestão populacional), que, através de bons conselhos, tornaria os indivíduos autônomos e economicamente moralizados.

Um Estado liberal demanda a liberalização de sua população, para que esta seja autônoma, se libertando dos blocos de dependência dispendiosos para o Estado, bem como a garantia de comercialização e circulação de capital. O autor comenta:

[...] há o polo assistencial que se apoia nessa definição liberal do Estado, remetendo para a esfera privada as demandas que lhe são formuladas em termos de direito ao trabalho $e$ à assistência. Portanto, um polo que utiliza o Estado como meio formal de divulgar certo número de conselhos e preceitos de comportamento a fim de transformar uma questão de 
direito político em questão de moralidade econômica. [...] nós forneceremos os meios para serdes autônomos através do ensino das virtudes da poupança e, de nossa parte, o mínimo direito será sancionar, através de uma tutela cuidadosa, as demandas de ajuda que ainda poderíeis solicitar, já que elas constituiriam o indício flagrante de falta de moralidade (DONZELOT, 2001: 56).

No Brasil, ganham força desde o final do século XIX os ditames de uma política econômica liberal que tensiona os modos de organização político-econômicos pautados na centralização estatal e nas relações sociais, ainda escravocratas, vigentes na sociedade brasileira. Os princípios do livre mercado, da meritocracia e do direito à propriedade privada se disseminam pelo tecido social (FOUCAULT: 2011) em estreita aliança com a medicina social, via saber médico, tensionando os arranjos vigentes e introduzindo paulatinamente sua função normalizadora em estrita articulação com o Estado. Inaugura-se, portanto, uma ação mais contínua e eficaz, adequada às novas relações capitalistas, possibilitando uma qualificação técnico-científica dos corpos, seus comportamentos e eficácias/ineficácias.

A função normalizadora institui curvas de normalidade a partir das quais se operam normas, ou seja, constrói-se um dispositivo de controle das subjetividades que se formaliza em meio às séries aleatórias do comportamento humano. Da "natureza" humana, emergem índices que distribuem os modos de vida em categorias menos ou mais favoráveis, concebíveis ou não concebíveis num modo de produção político-econômico capitalista.

[...] vamos ter uma identificação do normal e do anormal, vamos ter uma identificação das diferentes curvas de normalidade, e a operação de normalização vai consistir em fazer essas diferentes distribuições de normalidade funcionarem uma em relação às outras e em fazer de sorte que as mais desfavoráveis sejam trazidas às que são mais favoráveis. Temos portanto aqui uma coisa que parte do normal e que se serve de certas distribuições consideradas, digamos assim, mais normais que as outras. São essas distribuições que vão servir de norma. [...] O normal é que é primeiro, e a norma se deduz dele, ou é a partir desse estudo das normalidades que a norma se fixa e desempenha seu papel operatório. [...] não se trata mais de uma normação, mas sim, no sentido estrito, de uma normalização (FOUCAULT, 2009: 83).

No caso brasileiro, a partir do final do século XIX e início do século XX, a medicina sofreu influências das teorias eugênicas (Francis Galton) e da degenerescência (Morel), pautadas no darwinismo social, que propunham serem as determinações hereditárias não apenas dadas por traços físicos, mas também pelas capacidades mentais e morais do indivíduo e sua família. Portanto, seria necessário garantir proles mais sadias e o 
aperfeiçoamento da espécie em seus cruzamentos visando à correção moral dos desvios que a própria civilização estaria provocando na "evolução natural” da espécie.

Diversas interpretações da teoria de Darwin foram empregadas na análise das sociedades humanas e dos indivíduos, servindo para justificar diversas formas de dominação. [...] eis o caminho do darwinismo social. A ele, combinou-se a teoria das degenerescências, e a fatalidade da evolução humana acabou sendo substituída pela fatalidade degenerativa (LOBO, 2008: 112).

Há, contudo, conforme exposto anteriormente, uma associação do poder médico com as obras filantrópicas, no intuito de garantir maior legitimidade às intervenções pela caução das verdades científicas. Recai sobre o assistido todo o peso dessas verdades, que o qualificam e intentam transformar seus modos de vida para que não venham a 'degenerar a espécie humana' e desmoralizar a racionalidade econômica do liberalismo, pautada pelo livre comércio e individualização/naturalização dos problemas sociais.

Lobo (2008) indica que a questão primordial que se colocava naquele momento no país estaria em proporcionar ao Estado uma administração mais eficaz sobre a pobreza, e não uma mera apropriação, através da delegação desta incumbência à iniciativa privada.

Liberar a assistência à iniciativa privada, incentivá-la com subsídios, manter a racionalidade do equilíbrio entre ricos e pobres, mesmo que para isso seja necessário aumentar ainda mais o fosso que os separa - eis a tática do Estado liberal que, usando artifícios sempre mais sofisticados, se consolida no Brasil (LOBO, 2008: 339).

Junto à fecundidade do movimento médico-filantrópico, temos, a partir do início do século XX, as primeiras iniciativas de legislações voltadas ao mundo do trabalho, bem como lutas por direitos civis advindas de certo modo de organização da classe trabalhadora, que alcançaram, dentro de uma linguagem hegemônica do poder, uma legitimidade (BEHRING; BOSCHETTI: 2011).

Por um lado, os direitos sociais, sobretudo trabalhistas e previdenciários, são pauta de reivindicação dos movimentos e manifestações da classe trabalhadora. Por outro, representam a busca de legitimidade das classes dominantes em ambiente de restrição de direitos políticos e civis - como demonstra a expansão das políticas sociais no Brasil nos períodos de ditadura (1937-1940 e 1964-1984) (BEHRING; BOSCHETTI, 2011: 79).

Neste quadro, podemos observar que as medidas esparsas e frágeis de proteção social no país, até a década de 1930, estiveram pautadas num quadro restritivo de acesso a direito e no deslocamento da execução das políticas sociais à iniciativa privada, 
características estas persistentes e que nos ajudam a pensar também as práticas socioassistenciais contemporâneas.

É importante compreendermos que no contexto do final do século XIX e início do século XX, o liberalismo ‘à brasileira' não comportava a questão dos direitos sociais; estes foram incorporados sob pressão dos trabalhadores e com fortes dificuldades para sua implementação. "Essa situação começa a se alterar nos anos 1920 e sofrerá mudanças substanciais a partir dos anos 1930" (BEHRING; BOSCHETTI, 2011: 81). A economia e a política brasileiras foram fortemente abaladas pelos acontecimentos mundiais das três primeiras décadas do século XX, e mais ainda depois da crise de 1929-1932, quando se abre uma época de expansão acelerada das relações capitalistas no Brasil.

O movimento de 1930, que tinha por base a insurgência de uma elite ligada ao café, em seus preceitos de flexibilização econômica, industrialização, urbanização e ‘aburguesamento' dos modos de vida, precipitado com a ascensão de Getúlio Vargas ${ }^{3}$ ao poder, "foi sem dúvida um momento de inflexão no longo processo de constituição de relações sociais tipicamente capitalistas no Brasil" (BEHRING; BOSCHETTI, 2011: 105).

Contudo, tal proposta modernizadora não comportou procedimentos decisórios democráticos, visto que as mudanças desencadeadas a partir daí se deram sob uma ditadura, num processo de modernização conservadora. Ficaram pendentes, portanto, a regulamentação do trabalho e o enfrentamento dos problemas sociais, até então vistos como questão médico-filantrópica e policial.

Nesse sentido, o governo Vargas também enfrentou com a polícia os agrupamentos mais radicalizados do movimento operário insurgente. Porém, a partir de 1935, foi possível combinar essa atitude com uma forte iniciativa de regulamentação das relações de trabalho no país, neutralizando, desta forma, os conflitos gerados pelas condições de trabalho.

Esse esforço regulatório inicial, segundo Behring e Boschetti (2011), pode ser caracterizado como os anos de introdução da política social no Brasil, com características muito particulares, pautadas pela fragmentação e corporativismo, distante da perspectiva de universalização do acesso aos serviços socioassistenciais, previdenciários e de saúde.

Behring e Boschetti (2011) assinalam que certa centralização se inicia, em âmbito federal, com a criação da Legião Brasileira de Assistência (LBA), em 1942. Sua criação tinha como foco, inicialmente, o atendimento às famílias dos pracinhas envolvidos na 
Segunda Guerra, sendo coordenada pela primeira-dama, $\mathrm{Sr}^{\mathrm{a}}$ Darci Vargas, o que denota características de tutela e clientelismo na relação entre Estado e sociedade no Brasil, as quais transversalizam os processos de constituição das políticas sociais no país.

A LBA oferecia diferentes serviços, pautados no atendimento médico-social e materno-infantil; distribuição de alimentos para gestantes, crianças e nutrizes; assistência a crianças através de creches e abrigos; qualificação e iniciação profissional; liberação de instrumentos de trabalho; orientação jurídica para regularização e registro de entidades; programas de geração de renda; assistência ao idoso e portadores de deficiência e programa nacional de voluntariado, que se caracterizavam por sua focalização, diretividade e pontualidade.

Após a Era Vargas, é na ditadura militar que a política social insere-se em uma nova fase, "aliando o pacto social-democrata (sem os consensos produzidos nos anos de crescimento na Europa e Estados Unidos através do Welfare-State ${ }^{4}$ ) e uma redistribuição muito restrita dos ganhos de produtividade do trabalho que ampliou o mercado interno muito embora aquém de suas possibilidades - com uma política social exercida de maneira tecnocrática e conservadora" (BEHRING; BOSCHETTI, 2011:135), através da modernização do aparato varguista.

Portanto, as práticas socioassistenciais no Brasil, até a constituinte de 1988, não possuíam a conotação de direito social. Tais práticas eram dispostas, em sua maioria durante o século XX -, por instituições religiosas e, em seguida, organizações privadas que realizavam algum tipo de trabalho voltado para uma camada miserável da população, através de ações de filantropia respaldadas e financiadas pelo Estado.

\section{Política Nacional de Assistência Social e SUAS}

A partir da década de 1980 inicia-se o processo de democratização da sociedade brasileira, sinalizando para um novo desenho da Constituição a partir de políticas orientadas pelos princípios da universalização, responsabilidade pública e gestão democrática.

As experiências descentralizadas no campo da saúde começam a ganhar força, principalmente com a experiência da reforma sanitária, que traria um novo paradigma para o cuidado em saúde. Neste novo paradigma, ganham centralidade os conceitos de 
prevenção, promoção em saúde, a concepção de territorialização da assistência e controle social via participação popular, cujo exercício se dá através da construção de conselhos constituídos pela população que poderiam propor a melhor forma de gerenciar o seu cuidado. Assim, a Assistência Social começa a ganhar terreno para ser concebida como política pública estatal. Passa a ter unidade de ação, porém, como veremos à frente, permanece sendo focalizadora e meritocrática.

Com a constituinte de 1988, ocorre a institucionalização da Política de Assistência Social como componente da Seguridade Social, junto à Saúde e à Previdência Social. Em seu artigo 204, a Constituição Federal/1988 propõe o novo modelo da Assistência Social federativo:

1. Descentralização político-administrativa;

2. Normatização federal;

3. Coordenação tripartite;

4. Execução de programas;

5. Execução operada por gestor estadual, municipal e por entidades beneficentes e de assistência social;

6. Participação da população por meio de organizações representativas;

7. Políticas formuladas e com controle em todos os níveis;

8. Recursos financeiros da Seguridade Social.

A Política Nacional de Assistência Social (PNAS) ganha contornos a partir da delimitação de suas diretrizes, princípios e objetivos no ano de 1993, quando é aprovada a Lei Orgânica da Assistência Social (Lei n. 8742/93). No ano de 2004, há a proposição da Política Nacional de Assistência Social pelo Ministério de Desenvolvimento Social e Combate à Fome, que foi aprovada no mesmo ano pelo Conselho Nacional de Assistência Social - através da resolução 145 de 15 de outubro de 2004 - que intenta construir o desenho da assistência social na perspectiva da implementação do Sistema Único da Assistência Social (SUAS), bem como materializar as diretrizes da Lei Orgânica da Assistência Social. Contudo, apenas no ano de 2011 o SUAS é legalmente aprovado como sistema operador e organizador da política de assistência social em âmbito federal. 
Porém, no artigo 203 da CF/88, a assistência social surge como uma política social que "será prestada a quem dela necessitar, independentemente da contribuição à seguridade social". Ou seja, ao seu caráter público e universal é aberta uma exceção, referente a um conjunto de condicionantes/perfis para acesso a esta política (PNAS/2004:33), configurando uma especificação do público a se atender. Tal afirmação abre brechas para promover aproximações entre as práticas engendradas desde o período pré-republicano até meados do século XX, assumindo a gestão democrática e participativa, que possibilitariam produzir aberturas outras consonantes com o território e a heterogeneidade da vida que o singulariza, um lugar secundário na condução da política pública.

Segundo Behring e Boschetti (2011), a partir dos anos 1990, houve o desmonte das políticas sociais de caráter universalista, numa espécie de reformatação do Estado brasileiro para a adaptação à lógica do capital. Esta reformatação se deu através da adequação das políticas sociais a medidas pragmáticas e imediatistas, tornando o Estado organismo centralizador e unificador das "práticas", mas não efetivamente executor. A execução foi sendo delegada ao terceiro setor/iniciativa privada e/ou financiando e executando de maneira sucateada as políticas sociais, especialmente a Política de Assistência Social que esteve vinculada à LBA até meados da década de 1990.

Esta pequena introdução não pretendeu de forma alguma esgotar as discussões sobre o processo de constituição da Assistência Social, apenas apresentar elementos que a configuram como uma política formatada hibridamente, já que, segundo Oliveira (2010):

Essas práticas de assistência, grosso modo, não se colocam no tempo e no espaço de forma exclusiva. Como dissemos anteriormente, as práticas de auxílio momentâneo ainda persistem como forma de assistir, bem como, os bons conselhos. Ainda que cada vez mais a Assistência Social caminhe para uma tentativa de garantir os chamados direitos sociais, as práticas ditas assistencialistas, e também as de aconselhamento e normatização da vida, perduram como formas de assistir. Não há unidade em termos de práticas na Assistência Social, e são diversas entre si as práticas que a caracterizam (OLIVEIRA, 2010: 53).

Sendo assim, falar sobre este processo é uma tentativa de localizar a Assistência Social a partir das forças paradoxais que compõem este campo e dos discursos que a transformaram e transformam continuamente.

O SUAS prevê o atendimento integralizado e em diferentes níveis de proteção; além de ser uma política setorial é, ao mesmo tempo, universal e focalizada. Tais níveis de 
proteção seriam: o básico (CRAS), onde se preveniriam situações de risco; e o especial (Centro de Referência Especializado da Assistência Social - CREAS). Este último é dividido em média e alta complexidade, voltados, respectivamente, para o acompanhamento de situações em que já ocorreu violação de direitos, mas sem rompimento de vínculos familiares; e o último nível Serviço de Acolhimento Institucional (SAI), onde estes já ocorreram.

Tais níveis se esquematizam desta forma hierarquizada e acabam por ganhar uma conotação segmentada, dicotomizada, como se a realidade pudesse ser recortada e localizada a partir de ocorrências estanques, o que de certa forma garante o 'bom funcionamento' da máquina burocrática em suas diferentes emergências encaminhamentos, registro de atividades, quantificação do fazer, intersetorialidade, etc.

A tal perspectiva, que possibilita a resolução de situações de risco em níveis hierarquizados, também se atrela o conceito de território, que, conforme a PNAS/2004, é base para a organização do SUAS. Esta organização se dá através dos indicadores socioterritoriais disponibilizados pelo IBGE, no que tange à disposição demográfica e as taxas de desigualdade socioterritoriais. Assim como dos registros presentes nos equipamentos já instituídos nos municípios, como Conselhos Tutelares, Estratégia Saúde da Família, Ministério Público, dentre outros.

Na perspectiva da Assistência Social, o reconhecimento desta realidade permite pautar o que o Estado considera como espaços vulneráveis, territórios de risco e que demandam a existência de braços do Poder Público para dar conta das "desigualdades" e dos comportamentos variantes.

\section{Produzindo a Vulnerabilidade e o Risco Social}

Tais índices, indícios vulneráveis, permitem que acionemos a pergunta que intitula esse artigo: “A que veio o CRAS?”. Propomos aqui o acionamento de sua agonística, e não a busca de uma resposta. Esta pergunta pode estar vinculada ao jeito com o qual se implementam os equipamentos da Política de Assistência Social nos territórios, quase que unanimemente respaldada em indicadores sociais que qualificam ou não determinado espaço geográfico a receber um CRAS.

Citamos a Política Nacional de Assistência Social/2004 para facilitar a compreensão: 
[...] a Política Nacional de Assistência Social caracterizará os municípios brasileiros de acordo com seu porte demográfico associado aos indicadores socioterritoriais disponíveis a partir dos dados censitários do Instituto Brasileiro de Geografia e Estatística (IBGE). [...] A construção de indicadores a partir dessas parcelas territoriais termina configurando uma medida de desigualdade intraurbana. Esta medida, portanto, sofrerá variações de abrangência de acordo com as características de cada cidade, exigindo ação articulada entre as três esferas no apoio e subsídio de informações, tendo como base o Sistema Nacional de Informações de Assistência Social e os censos do IBGE, compondo com os campos de Vigilância Social, locais e estaduais, as referências necessárias para sua construção. Porém, faz-se necessária a definição de uma metodologia unificada de construção de alguns índices (exclusão/inclusão social, vulnerabilidade social) para efeitos de comparação e definição de prioridades da Política Nacional de Assistência Social (PNAS/2004: 45).

Tudo isso, de acordo com a PNAS/2004, garantirá maior capacidade gerencial nas três esferas de governo e o aprimoramento dos instrumentos de gestão, introduzindo o geoprocessamento como ferramenta da Política de Assistência Social para garantir a demarcação das populações e territórios vulneráveis.

Em novembro de 2011, foi publicado, pelo Ministério de Desenvolvimento Social e Combate à Fome, o Manual de Instruções para o Registro das Informações Especificadas no CRAS e CREAS em conformidade à resolução $n^{\circ}$ 04/2011 da CIT (Comissão Intergestores Tripartite), que institui os parâmetros nacionais para o registro das informações relativas aos serviços ofertados nos CRAS e CREAS. Neste documento, está prevista a criação de um sistema operacional em que serão descritas de maneira objetiva as atividades realizadas em período mensal nos equipamentos municipais da Assistência Social.

Conforme o manual, os dados registrados devem produzir informações que auxiliem o planejamento e aprimoramento da oferta dos serviços no município. Dentre estas informações, constam: lista de famílias/usuários (com nome dos responsáveis) que ingressaram no acompanhamento de algum serviço ofertado nos equipamentos CRAS/CREAS; quantidade de novas famílias inseridas no acompanhamento socioassistencial; quantidade de famílias em extrema pobreza; famílias beneficiárias do Programa Bolsa-Família; famílias do Programa Bolsa-Família em descumprimento de condicionalidades; bem como o tipo de solicitação efetuada pelas famílias e os encaminhamentos consequentes. 
Além disso, o manual dispõe de uma ampla especificação referente ao modo de caracterizar e acessar cada modalidade de atendimento, especificando o que caberia a um atendimento individual, coletivo, ou a um acompanhamento familiar.

[...] considera-se acompanhamento familiar no âmbito do PAIF ou do PAEFI aquele acompanhamento realizado por meio de atendimentos sistemáticos e planejado com objetivos estabelecidos, que possibilitem às famílias/indivíduos o acesso a um espaço onde possam refletir sobre sua realidade, construir novos projetos de vida e transformar suas relações, sejam elas familiares ou comunitárias (2011: 2).

Todo este aparato conceitual, em suas definições claras que figuram um modo mecânico e tecnicista para atender as demandas heterogêneas que nos surgem, objetiva constituir um objeto pleno para a política de assistência social, visando, ainda que não explicitamente, a garantia de uma identidade, uma forma, tendências únicas, centralizadoras, dirigistas, planificadoras e tecnocráticas. Sendo assim, é possível justificar as ações que foram implantadas, bem como garantir a ampliação de suas redes de atuação.

As ações planificadoras e centralizadoras se complementam através do conceito de vigilância social, que, de acordo com a PNAS/2004, se configura como um instrumento eficaz para a organização do SUAS, visto que "refere-se à produção, sistematização de informações, indicadores e índices territorializados das situações de vulnerabilidade e risco pessoal e social que incidem sobre famílias/pessoas nos diferentes ciclos de vida. [...] Os indicadores a serem construídos devem mensurar no território as situações de riscos sociais e violação de direitos" (PNAS/2004: 40).

Na citação abaixo, fica claro o que a PNAS/2004 considera como público-alvo de sua intervenção:

[...] cidadãos e grupos que se encontram em situações de vulnerabilidade e risco, tais como: famílias e indivíduos com perda ou fragilidade de vínculos de afetividade, pertencimento e sociabilidade; ciclos de vida; identidades estigmatizadas em termos étnico, cultural e sexual; desvantagem pessoal decorrente de deficiências; exclusão pela pobreza e, ou, no acesso às demais políticas públicas; uso de substâncias psicoativas; diferentes formas de violência advindas do grupo familiar, grupo e indivíduos; inserção precária ou não inserção no mercado de trabalho forma e informal; estratégias $e$ alternativas diferenciadas de sobrevivência que podem representar risco pessoal e social (PNAS/2004:33).

Todos os índices são formados a partir da produção de um olhar, de um regime discursivo e de normalidade, em meio aos quais a vulnerabilidade é produzida como 
problema social. É necessário controlar, tomar o humano, a vida, em sua extensão numérica, lá mesmo onde é morta.

Castel (1987) nos ajuda a pensar que, em meados do século XX, há uma mudança de paradigma nas práticas médico-psicológicas de cuidado no que se refere às intervenções terapêuticas diretas sobre o indivíduo. Ocorre uma subordinação da atenção profissional aos complexos mecanismos de gestão populacional que iniciam sua implementação através da informatização dos dados/índices acerca das variações do comportamento humano.

O saber médico-psicológico torna-se assim, o instrumento de uma política de gestão diferencial das populações mais do que o cuidado [...] Na medida em que esta orientação pode se apoiar ao mesmo tempo em tecnologias altamente sofisticadas como a informática, e numa nova administração da Ação Social reorientada ao redor da prevenção sistemática dos riscos (CASTEL, 1987: 101).

Emerge, portanto, uma gestão sistemática dos riscos sociais/pessoais como forma de operar o controle sobre os processos de subjetivação que ocorrem em meio aos modos de vida da população. $\mathrm{O}$ autor nos esclarece que tal perspectiva se tornou proeminente a partir da instauração de um novo dispositivo jurídico-administrativo, em meados do século XX: a deficiência.

Esta não se confunde absolutamente com o conceito de alienado, deficiente mental ou perturbado mental, mas realiza uma mistura de categorias heterogêneas: retardado, deficiente físico, inadaptado, diminuído, menor, enfermo, incapaz e desvalido. Ou seja, a deficiência coloca em evidência as performances sociais, a eficiência ou ineficiência de determinada categoria para o trabalho, a escola etc. Ela produz e depende de medidas de eficiência do comportamento, intentando encontrar respostas objetivas para sua adequação social, quais sejam: operar a separação de certos grupos de alunos em salas especiais em função de sua inferioridade ou superioridade, criar vagas de emprego adequadas para aqueles que possuem algum tipo de defasagem, ou, conforme nos diz a política de assistência social, a qualificação de modos e condições de vida como vulneráveis e de risco.

Junto às práticas agenciadas em torno da deficiência, há toda uma afirmação de inclusão daqueles que por tanto tempo foram alienados da vida social, ou seja, há a promessa de desospitalização e despsiquiatrização daqueles que estavam condenados ao aprisionamento de um hospital psiquiátrico. 
A atenuação daquilo que se chama deficiência se dá, portanto, através dos processos de aprendizagem, e não das terapias. Ou seja, "trabalho para os adultos, resultados escolares para as crianças constituem o duplo horizonte de valores de eficiência, a partir dos quais a deficiência se inscreve como falta" (CASTEL, 1987: 106).

Este novo dispositivo, portanto, não fala de uma patologia, mas de uma desigualdade; há sempre uma inferioridade medida, que é assimilada como um déficit social. As histórias das pessoas são naturalizadas, e aquilo que há de diferencial é enquadrado no amplo espectro da deficiência. Porém, muito embora haja esse compromisso com a despsiquiatrização, os diagnósticos médico-psicológicos continuam a servir de caução para um julgamento normativo. É preciso que se confirmem cientificamente as deficiências para dar legitimidade aos discursos sobre as deficiências.

Sendo assim, os profissionais que atuam nesta frente acabam se tornando especialistas em determinado assunto, colaborando com a decisão de outras instâncias acerca da criação de normas ou com a alimentação de dados para um sistema informativo que acondiciona e produz índices e taxas de risco social/pessoal. O saber médicopsicológico-social serve, portanto, como "fundamento de legitimidade e de correia de transmissão num funcionamento institucional, cujo domínio lhe escapa completamente.’ (CASTEL, 1987: 110).

Tais saberes se tornam acessórios, auxiliares de uma política administrativa completamente definida pelas exigências de gestão das populações e seus riscos decorrentes, riscos estes que podem ser qualificados como o perigo de determinados grupos se desviarem daquilo que foi traçado como a norma para o cidadão médio.

Hillesheim e Cruz (2008) nos alertam que a "noção de risco possibilita neutralizar a ideia de perigo, a partir da antecipação do mesmo e da vigilância sobre as situações que possam causá-lo" (p. 195), ou seja, ao lado de uma política que torna possível a mensuração da vida, também ficam evidentes práticas preventivas que se constituem pela antecipação de uma possível ocorrência de perigo.

Todos os índices e suas curvas de variáveis daquilo que pode incidir sobre um território ou indivíduos permitem fazer nascer um território vulnerável. Há uma sutil relação entre risco e vulnerabilidade, visto que aqueles que porventura possam ser atingidos 
por riscos previstos numa equação matemática estão vulneráveis às suas ações e, portanto, estão suscetíveis às consequências de tais variáveis, tanto pessoais quanto coletiva.

O que opera aqui é uma lógica probabilística: quanto maior for a presença de fatores de risco, maior a vulnerabilidade desta população e, portanto, maior a possibilidade de ocorrência de algum dano, fazendo-se necessária a intervenção sobre o perigo, deslocando-o de uma ordem do imponderável e tornando-o passível de previsão e controle (HILLESHEIM; CRUZ, 2008: 196).

No momento em que se passa a considerar a vulnerabilidade como um processo e não um estado - incorporando a probabilidade de sofrer um dano por ocorrências inesperadas, sendo estas compostas numa lógica probabilística -, permitem-se intervenções com vieses preventivos.

A instituição vulnerabilidade conforma práticas que em seus atravessamentos interferem diretamente sobre os modos de vida dos usuários, pois a "introdução da noção de vulnerabilidade abre espaço para a possibilidade de intervenção, isto é: diminuindo-se a vulnerabilidade mediante ações mitigadoras, pode-se diminuir o risco e, consequentemente, o perigo.” (HILLESHEIM; CRUZ, 2008: 196).

As intervenções profissionais (médico-psicológicas-sociais) conformariam, antes de tudo, as categorias de indivíduos para assinalá-los a lugares precisos. O diagnóstico do especialista representaria, portanto, a radiografia científica de um processo de distribuição das populações - seus grupos e incidências de riscos - em circuitos especiais, localidades para o cuidado de cada especificidade em questão. O CRAS poderia absorver, em certa medida, esses grupos, oferecendo núcleos de convivência e acesso a uma rede de assistência/acionamento das instâncias de controle: sejam as outras políticas sociais, os conselhos tutelares e de direitos e o judiciário. Institucionaliza-se uma perspectiva de direito social que paradoxalmente operacionaliza/visibiliza a própria violação dos direitos.

A violação se torna imprescindível para o acesso ao direito, seja pelos esquadrinhamentos que demarcam a incidência do risco (social, ambiental, geográfico), seja pelo risco do indivíduo violar o seu direito ou o direito alheio. Forja-se, de maneira compatível, violação/garantia do direito; inseparável equação que dimensiona o corpo vulnerável, sua abstração ganha concretude a partir de suas falhas morais e dos delitos que porventura se lhe possam associar. 
Para se desvencilhar dessa grotesca equação que vincula risco, vulnerabilidade e violação de direitos, é preciso retorcer as curvas e deformar o metro-padrão: operações difíceis, que exigem coragem e atrevimento. Atrever-se como trabalhador, atrever-se como usuário, na 'burla' de uma política, de um modo de pensar política social, nos possibilita uma aliança com a vida naquilo que ela traz como agonística, e não com o que nela agoniza. Operar tal desvio é de certa forma romper com uma relação que objetifica usuários e profissionais e requer, no cotidiano do trabalho, a produção de aberturas de sentidos outros para os encontros, tornando-os matéria-prima (ou matéria viva) das subjetividades que constroem esta política como, de fato, política pública.

\section{Conclusão}

O presente artigo teve por objetivo tensionar algumas questões fundamentais no funcionamento da política de Assistência Social no contemporâneo, partindo de perguntasresistência que problematizaram as táticas de gerência/governo dos corpos que habitam os 'ditos' territórios vulneráveis e de risco onde se inserem os equipamentos da Assistência Social. Como desnaturalizar, produzir dissonâncias e estranhezas, naquilo mesmo que forja a institucionalização da PNAS e seus dispositivos, qual seja, a institucionalização de um horizonte de violação de direitos como acesso à garantia de direito?

O que vamos percebendo neste exercício de desnaturalizar, de estranhar e, algumas vezes, desobedecer ao preconizado é a necessidade/urgência de uma delicadeza para espreitar, na brutalidade dos fatos, o que é índice intensivo de movimento-desvio.

Neste exercício, pudemos também compreender as estratégias de resistência da vida (que questionam a existência do CRAS ou gesticulam automaticamente como forma de se preservar frente às tutelas e aprisionamentos apresentados) que insurgem inventivamente em meio a estas enunciações, ou seja, os movimentos cotidianos que interpelam aquilo que intenta tornar a vida previsível e matéria de governo, que a transformam em objeto de intervenção e sujeita a práticas tutelares que se agenciam e são agenciadas pelos modos de operar a Política de Assistência Social na contemporaneidade.

A que veio o CRAS? Que ajuda se presta? O que escutávamos ou queríamos escutar? Escutávamos o quê? O que poderia vir a ser um comportamento de risco, os problemas, as carências, as impotências? 
Temos apostado, em meio às indagações, numa escuta-experimentação, aquela que acolhe a demanda do outro não como exercício de piedade ou numa perspectiva tecnicista que intenta ensurdecer os desvios e tomá-los como matéria sujeita à correção, mas como abertura aos movimentos da vida que se forjam em meio àquilo que a pretende naturalizada.

Afirmar a escuta como experimentação significa indicar que as necessidades do outro, com o qual lidamos, precisam ser incluídas, não por uma operação humanista e piedosa, mas como elemento perturbador e analisador dos modos de vida naturalizados [...] uma escuta sensível implica, necessariamente, ouvir os vestígios, ver os movimentos [...] colocar em análise nossos preconceitos, endurecimentos, indiferenças, intolerâncias (HECKERT, 2007: 10).

O que Heckert (2007) nos aponta é que é preciso ouvir o outro como um elemento perturbador de nossas formas instituídas, como se ouve um ruído estranho. O desvio, portanto, que poderia ser arremessado a atitudes preventivas e moralizadoras, pode se aliar a uma prática 'psi' clandestina que se engravide da heterogeneidade dos modos possíveis de existir, que possa se aliar às indeterminações do vivo, que possa desinventar objetos. Inspirados em Manoel de Barros, poderíamos pensar: Como dar à assistência social função que não é da assistência social? Como ensinar ao CRAS função que não é de CRAS?

Apostamos, portanto, em uma escuta que mobilize essa desinvenção, que reverbere as indignações, produzindo inventivos e potentes efeitos nos modos de fabricação do cuidado na assistência social.

Escutar como um engravidar... Desta escuta a pesquisa pôde produzir filhotes prenhes, visto que ela se deu em meio à agonia de afirmar palavras que ainda não tinham idiomas. Ela pôde desinventar e ser desinventada por tudo aquilo que no percurso cortou o aprendido. É preciso desaprender para escutar a experiência, pois ela não se alia, primordialmente, aos saberes instituídos. Ela não se pauta no IBGE, no CENSO SUAS, no IPEA. Ela é grávida de práticas, muitas práticas. Práticas que desassossegam os índices. É preciso inventar novas ferramentas para responder (ou não) a tantas perguntas inventadas em inusitados processos de fabulação.

Fabular, escutar o 'ronco surdo das batalhas' (FOUCAULT, 2009a), estar poroso às interferências das perguntas-resistência, intensifica a força das experiências, em suas indeterminações e singularizações, que podem também ganhar consistência quando aliadas a práticas profissionais marginais. Apostamos em uma prática 'psi' clandestina, atenta aos movimentos e sussurros da vida. 


\section{Referências}

BEHRING, E. R.; BOSCHETTI, I. Política social: fundamentos e história. 9 ed. São Paulo: Cortez, 2011.

CASTEL, R. A gestão dos riscos: da antipsiquiatria à pós-psicanálise. Rio de Janeiro: Livraria Francisco Alves, 1987.

DELEUZE, G.; GUATTARI, F. Mil Platôs: capitalismo e esquizofrenia. Vol.I. São Paulo: Ed.34, 1995.

DONZELOT, J. A polícia das famílias. São Paulo: Graal, 2001.

FOUCAULT, M. Em defesa da sociedade. 1 ed. (4 a tiragem). São Paulo: Martins Fontes, 2005.

FOUCAULT, M. Microfísica do poder. Rio de Janeiro: Graal, 2011.

. Segurança, território, população. 1 ed. (2a tiragem). São Paulo: Martins Fontes, 2009.

. Vigiar e punir. 36 ed. Rio de Janeiro: Vozes, 2009a.

HECKERT, A. L. C. Escuta com cuidado: o que se passa nos processos de formação e de escuta?. In: PINHEIRO, R; MATTOS, R, A (Org.). Razões públicas para a integralidade em saúde: o cuidado como valor. 1 ed. v.1. Rio de Janeiro: ABRASCO/CEPESC, 2007. pp. 199-212.

HECKERT, A. L. C. Narrativas de resistências: educação e políticas. Tese de Doutorado em Educação. Niterói: UFF, 2004.

HILLESHEIM, B.; CRUZ, L. R. Risco, vulnerabilidade e infância: algumas aproximações. Psicologia e sociedade, n. 20, 2008. pp. 192-9.

LOBO, L. Os infames da história: pobres, escravos e deficientes no brasil. Rio de Janeiro: Lamparina, 2008.

LOURAU, René. Análise Institucional e Práticas de Pesquisa. Rio de Janeiro: Ed. UERJ,1993.

MINISTÉRIO DO DESENVOLVIVIMENTO SOCIAL E COMBATE À FOME. Orientações técnicas sobre o PAIF. v. 1. Brasília, 2012.

. Política nacional de assistência social. Brasília, 2004.

OLIVEIRA, C. M. C Atenção básica na assistência social: entre miséria necessária, artes de governar e redes de solidariedade. Dissertação de Mestrado em Psicologia Institucional. UFES, 2010.

SILVA, R. N. A Invenção da Psicologia Social. Petrópolis: Vozes, 2005.

VEYNE, P. Como se escreve a história (1971) e Foucault revoluciona a história. Brasília: UNB, 1978. 
Paulo Armando Esteves Martins Viana Trabalhador do SUS e doutorando do PPFH/UERJ

E-mail: pauloarmando83@yahoo.com.br

Claudia Elizabeth Abbês Baeta Neves

Professora aposentada dos cursos de graduação e pós-graduação em Psicologia da

UFF/Niterói

E-mail: claudiaabbes375@gmail.com

\begin{abstract}
${ }^{1}$ VIANA, P. A Que Veio o CRAS?
${ }^{2}$ Biopolítica é um conceito construído por Foucault (2009) ao pensar o funcionamento de um novo diagrama do poder que emerge no século XIX visando a gestão da vida a partir da otimização da qualidade biológica das populações. Além disto, a biopolítica está vinculada ao fortalecimento do Estado, da burguesia, bem como à formação de um dispositivo médico-jurídico visando a medicalização e normalização da sociedade.

${ }^{3}$ Getúlio Vargas foi presidente do Brasil em dois períodos: o primeiro, por 15 anos (1930-1945) ininterruptos, e o segundo, quando foi eleito por votação direta, do ano de 1951 ao de 1954.

${ }^{4} \mathrm{O}$ Welfare-State (Estado de bem-estar social) configura-se por uma "gama de reformas sociais intrínsecas ao capitalismo, sob a pressão dos trabalhadores, com uma ampliação sem precedentes do papel do fundo público, desencadeando medidas de sustentação da acumulação, ao lado da proteção ao emprego e do atendimento de algumas demandas dos trabalhadores" (BEHRING; BOSCHETTI, 2011: 149).
\end{abstract}

